\title{
An Analytical Investigation of Modular Concrete-filled Square Steel Tubes based on the Strain Compatibility
}

\author{
Seon-Chee PARK ${ }^{1}$, Won-Kee HONG ${ }^{1}$, Hyo-Jin $\mathrm{Ko}^{2}$ \\ ${ }^{1}$ Department of Architectural Engineering , \\ Engineering College, Kyung Hee University, \\ 1732 Deogyeong-daero, Giheung-gu, Yongin-si, Gyeonggi-do, Republic of Korea \\ ${ }^{2}$ AJU Corporation, \\ 26 Geonji-ro 86 beon-gil, Seo-gu, Incheon, AJU R\&D Center, 404-812 Republic of Korea \\ *Corresponding author's e-mail: hongwk@khu.ac.kr
}

\begin{abstract}
Concrete-filled square steel tubes demonstrating good structural resistance against vertical and lateral loads can be used for modular constructions. To promote the applications of the composite tubes to modular construction, it is important to provide simple but accurate analytical methods that can elucidate the structural behaviour of the composite tubes. A number of international design codes are known to calculate the flexural load bearing capacity of the concrete-filled square steel tubes. Some, however, are not predicting the behaviour of the composite tubes accurately. An analytical investigation of concrete-filled square steel tubes was presented in this paper. A strain compatibility based design method considering confinement effect of concrete in tubes was proposed to estimate the flexural strength of composite steel tube filled with concrete. Nominal moment capacities estimated in accordance with the standards of AIJ(Japan), AISC(USA), Eurocode4(Europe) and KSSC(Korea) were compared with the analytical value obtained using the strain compatibility based design method. Since the design method with strain compatibility proposed in the study reflects the concrete confinement with accurate estimation of the neutral axis of composite tube section, the flexural moment capacity of composite tube section can be accurately obtained. The test results of other researchers including $\mathrm{Lu}$ and Kennedy were used to verify the reliability of the proposed design method. These experimental results were shown to be the best correlated with the analytical results provided by the proposed method in this paper than any other analytical methods proposed by the international codes that were used to calculate flexural load bearing capacity. The $6 \%$ of errors were demonstrated by the proposed approach while bigger errors were observed in the analytical calculations of other design codes as large as $17 \%$.
\end{abstract}

\section{KEYWORDS}

Concrete-filled square steel tubes; modular construction; flexural moment; strain compatibility; concrete confinement

\section{INTRODUCTION}

The American Institute of Steel Construction (AISC, 2010) proposes the plastic stress 
distribution and the strain compatibility methods as solutions to estimate the flexural strength of a composite cross section. The strain compatibility method assumes a linear distribution of strain over cross sections and calculates the stress of each material to estimate the strength of the cross section. The maximum strain of concrete is assumed to be $\varepsilon_{c}=0.003$ in general. As the strain compatibility method satisfies compatibility and equilibrium conditions as long as an accurate constitutive equation is given for each material, it can produce very accurate analysis for all cases. The plastic stress distribution method is a simplified version of the strain compatibility method that estimates the bearing capacity of a cross section in reference to stress distribution in the plastic state. Concrete-filled square steel tube elements do not consider the confinement effect of the steel member when it reaches yield stress under tension or compression. The strength of the concrete-filled square steel tube member is calculated on the assumption that concrete shows a plastic stress distribution in which it reaches $0.85 f^{\prime}{ }_{c}$ of stress under compression.

The Eurocode 4 (2004) estimates the bearing capacity of an element on the assumption of full plastic stress distribution. Concrete and steel are assumed to be completely attached to each other and the stress of concrete and steel in their ultimate state is considered to be in the plastic state. The Eurocode 4 does not provide a specific design equation for calculating the flexural strength of concrete-filled steel tubes but proposes the application of the rigid-plastic theory for ultimate moment performance. It, therefore, proposes a design equation based on plastic moment.

The Architectural Institute of Japan (AIJ) (2001) design code suggests the allowable stress and the ultimate strength design methods for earthquake-proof designs, stipulating that the bearing capacity of concrete filled tube(CFT) be estimated by the superimposed strength method (Morino and Tsuda, 2003). As the AIJ design code estimates and adds together the bearing capacities of concrete and steel, their strain does not have to match.

The flexural strength of the concrete-filled square steel tube column is estimated herein according to the steel structure design code of the Korean Society of Steel Construction (KSSC) (2011). The Korean design code proposes two methods for estimating the flexural strength of the concrete-filled square steel tube column - the plastic stress distribution and the strain compatibility methods that are identical to those set forth in the AISC design code. Tensile strength of concrete is ignored in determining the nominal strength of the composite cross section. The strain compatibility design approach proposed in this paper applies the concrete confinement effect suggested by Mander et al. (1988) and the equivalent stress block coefficient $\alpha$ and $\beta$ proposed by Karthik and Mander (2011) and reflects the increase in strength from the stress-strain correlation of the confined concrete. The proposed strain compatibility design approach linearizes the strain of the composite element to calculate the strain of all constitutive elements as proportional expressions with the strain of the top surface of the concrete in the compressed area $\left(\varepsilon_{c}\right)$ and neutral axis (c). The equilibrium equation is established at the location of the neutral axis based on the stress state of re-bar and steel member which is the constitutive elements of construction members. The equilibrium equation is again converted to a first-degree or second-degree equation regarding the neutral axis (c) and the flexural strength according to the strain of the top surface of the concrete in the compressed area $\left(\varepsilon_{c}\right)$ that can be estimated by calculating the value of the neutral axis (c). The proposed strain compatibility design approach is associated with the advantage of being able to accurately predict the stress produced for all 
structural components of the strain covering the pre-yield limit state, yield limit state, maximum load limit state, and failure limit state. (Hong et al., 2009 and 2010) To give consideration to the confinement effect of concrete, the stress-strain diagram shown in Figure. 1 (Mander et al., 1998) and Equation (1) (Popovics, 1973) are used. The Equation (2) indicates the maximum compressive strength of confined concrete while the Equations (3) and (4) represent the factor $\left(\alpha_{1}\right)$ that increases the concrete compressive strength, and the factor $\left(\alpha_{2}\right)$ that is the horizontal to the vertical ratio of square column, respectively. (Mander et al. 1998)

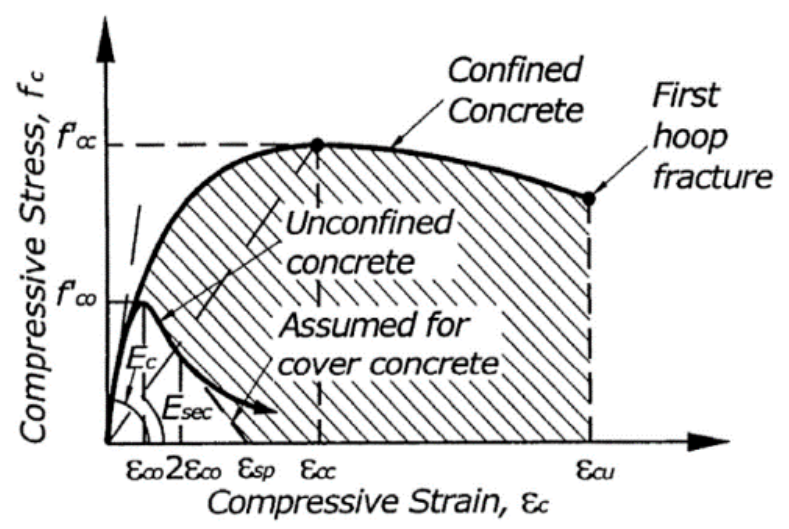

Figure 1. Stress-Strain Relation for Confined Concrete (Mander et al. 1998)

$$
\begin{gathered}
f^{\prime}{ }_{c}=\frac{f^{\prime}{ }_{c c} x \gamma}{\gamma-1+x^{\gamma}} \\
f^{\prime}{ }_{c c}=k_{c} f^{\prime}{ }_{c o}, \quad k_{c}=\alpha_{1} \alpha_{2} \\
\alpha_{1}=\left(-1.254+2.254 \sqrt{1+\frac{7.94 f^{\prime}}{f^{\prime}{ }_{c o}}}-\frac{2{f^{\prime}}_{l}}{f^{\prime}{ }_{c o}} \pi r^{2}\right) \\
\alpha_{2}=\left\{1.4 \frac{f_{l}}{F_{l}}-0.6\left(\frac{f_{l}}{F_{l}}\right)^{2}-0.8\right\} \sqrt{\frac{7.94 f_{l}}{f^{\prime}{ }_{c o}}}+1
\end{gathered}
$$

Where, $f^{\prime}{ }_{c c}=$ compressive strength of confined concrete, $f^{\prime}{ }_{c o}=$ compressive strength of unconfined concrete, $f^{\prime}{ }_{l}=$ effective confining lateral stress, $f_{l}=$ minimum confining lateral stress, $F_{l}=$ maximum confining lateral stress

With the confining constitutive relationships, a strain compatibility design approach is proposed to consider the confinement effect of concrete confined by square steel tubes to estimate the accurate flexural strength of concrete-filled square steel tubes. 


\section{MODULAR CONSTRUCTION OF CONCRETE-FILLED SQUARE STEEL TUBES}

The modular vertical building/extension construction method using concrete-filled square steel tubes studied herein features joint construction techniques whereby the upper square tube steel column with funnel is slid/fit into the lower column with a guide tube as shown in Figure 2 and Figure 3.

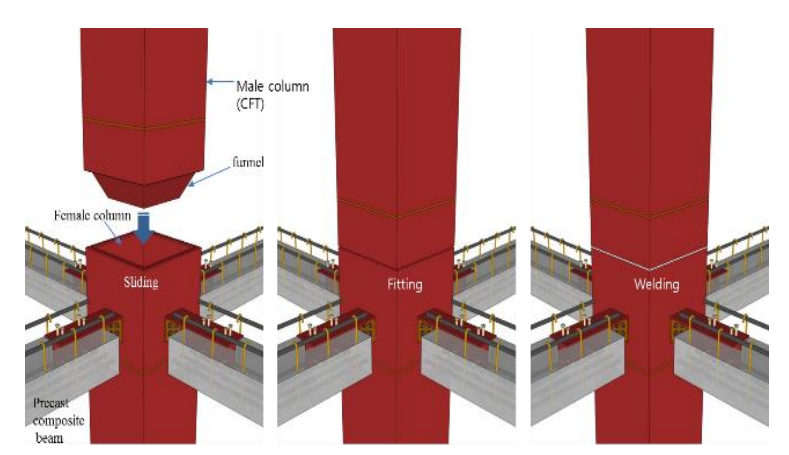

Figure 2. Modular Vertical Extension Concept for New Building

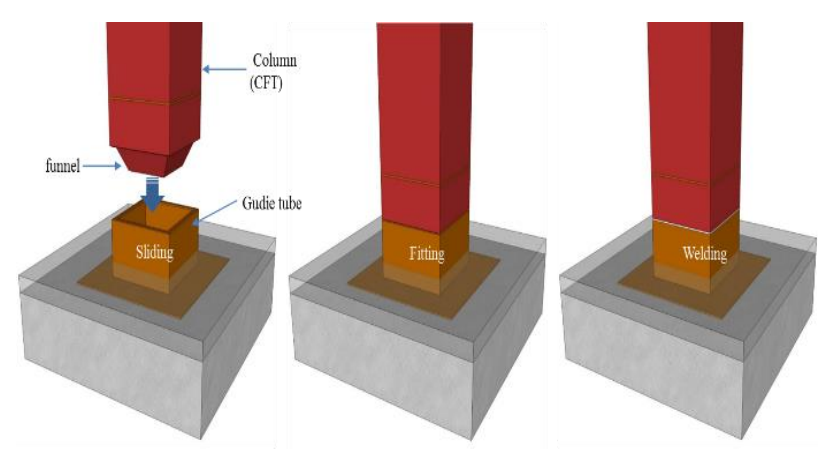

Figure 3. Modular Vertical Extension Concept for Existing Building

For remodeling of apartment buildings, modular construction of vertically extended frames adopting concrete-filled square steel tube columns are assembled in advance on the ground and lifted by crane onto the top of the building where they are built in layers using a sliding/fitting technique. This has advantages including a quick construction time, verticality of column maintained by guide tubes, and simplicity of construction. A concrete-filled steel tube column has efficient aseismic capacities ensured by high ductility and energy absorption performance, and better lateral load bearing capability due to the efficient combination of steel tube and concrete. In addition, concrete-filled steel tube columns are more advantageous for local buckling due to the confinement effect of concrete and it is associated with less bearing capacity degradation because of no loss of cross section after crushing.

\section{RESEARCH METHODS}

The design formulae proposed by the AISC of the United States, the AIJ of Japan, and the KSSC 
of Korea do not consider the filling effect of concrete for square steel tube. The Eurocode 4 estimates the resisting moment capacity of composite cross section with plastic analysis. Plastic analysis assumes a strain over the shear plane and estimates the resisting moment capacity, assuming ultimate strength of concrete, yielding of steel frame and re-bar over the shear plane. When estimating the maximum bearing capacity of the elements, the AIJ assumes a completely plastic state of steel tube, which indicates that the steel elements bear all the loads and thus excludes the composite effect of concrete from the calculation. Hence, the AIJ approach tends to underestimate the performance of elements. The AISC proposes a selective application of the strain compatibility method and plastic stress method to estimate the load-bearing capacity of the composite elements. In the case of square steel tube elements, however, the confinement effect of concrete is not considered and the concrete strength is $0.85 f^{\prime}{ }_{c}$ that is suggested in the existing design codes, which renders it difficult to calculate accurately pure flexural strength of concretefilled steel tube columns.

The reliability of the strain compatibility design approach is studied herein by comparing the experimental data presented by researchers including Tommi and Sakino (1979), Lu and Kennedy (1994), Zhang and Shahrooz (1997), Uy (2000), Han (2004), and Probst et al. (2010) and values suggested in the AIJ, AISC, Eurocode 4, and KSSC design codes with the analytical results by the proposed strain compatibility design approach which considered the confinement effect of concrete. The Equation (5) represents the equilibrium equation at maximum load limit state in the proposed strain compatibility approach. In addition, the equation (5) was used to calculate the location of neutral axis while the Equation (6) was used to calculate the nominal moment capacity $\left(M_{n}\right)$.

$$
\begin{aligned}
& \alpha f^{\prime}{ }_{c c} \beta\left(b-2 t_{w}\right)\left(c-t_{f}^{\prime}\right)+A^{\prime}{ }_{f} F_{y}+A^{\prime}{ }_{w p} F_{y}+A^{\prime}{ }_{w n y}\left(\frac{1}{2} E_{s} \varepsilon_{s y}\right) \\
& =A_{f} F_{y}+A_{w p} F_{y}+A_{w n y}\left(\frac{1}{2} E_{s} \varepsilon_{s y}\right)
\end{aligned}
$$

Where, $\left.\quad A^{\prime}{ }_{w p}=2 t_{w}\left\{\left(1-\frac{\varepsilon_{s y}^{\prime}}{\varepsilon_{c}}\right)\left(c-t_{f}\right)\right\}, A^{\prime}{ }_{w n y}=2 t_{w} \frac{\varepsilon_{s y}^{\prime}}{\varepsilon_{c}}\left(c-t_{f}\right)\right\}$,

$$
A_{w p}=2 t_{w}\left\{d-c-\frac{\varepsilon_{s y}}{\varepsilon_{c}}\left(c-t_{f}\right)-t_{f}\right\} \text {, and } A_{w n y}=2 t_{w} \frac{\varepsilon_{s y}}{\varepsilon_{c}}\left(c-t_{f}\right)
$$

$M_{n}=\alpha{f^{\prime}}^{\prime}{ }_{c c} \beta\left(b-2 t_{w}\right)\left(c-t_{f}^{\prime}\right)\left(c-t_{f}^{\prime}-\frac{\beta c}{2}\right)+A_{f}^{\prime} F_{y}\left(c-\frac{t_{f}^{\prime}}{2}\right)+2 t_{w}\left\{\left(1-\frac{\varepsilon_{s y}^{\prime}}{\varepsilon_{c}}\right)(c-\right.$

$\left.\left.t_{f}\right)\right\} F_{y}\left\{\frac{1}{2}\left(c-t_{f}-\frac{\varepsilon_{s y}^{\prime}}{\varepsilon_{c}}\left(c-t_{f}\right)\right)+\frac{\varepsilon_{s y}^{\prime}}{\varepsilon_{c}}\right\}+2 t_{w} \frac{\varepsilon_{s y}^{\prime}}{\varepsilon_{c}}\left(c-t_{f}\right)\left(\frac{1}{2} E_{s} \varepsilon_{s y}\right) \frac{2}{3}\left(\frac{\varepsilon_{s y}^{\prime}}{\varepsilon_{c}}\left(c-t_{f}\right)\right)+$

$A_{f} F_{y}\left(d-c-\frac{t_{f}}{2}\right)+2 t_{w}\left\{(d-c)-\frac{\varepsilon_{s y}}{\varepsilon_{c}}\left(c-t_{f}\right)-t_{f}\right\} F_{y}\left\{\frac{1}{2}\left(d-c-t_{f}-\frac{\varepsilon_{s y}}{\varepsilon_{c}}\left(c-t_{f}\right)\right)+\right.$

$\left.\frac{\varepsilon_{s y}}{\varepsilon_{c}}\left(c-t_{f}\right)\right\}+2 t_{w} \frac{\varepsilon_{s y}}{\varepsilon_{c}}\left(c-t_{f}\right)\left(\frac{1}{2} E_{s} \varepsilon_{s y}\right) \frac{2}{3}\left(\frac{\varepsilon_{s y}}{\varepsilon_{c}}\left(c-t_{f}\right)\right)$

\section{RESULT AND DISCUSSION}

The flexural strength of the member $\left(\boldsymbol{M}_{\text {ext }}\right)$ measured by the preceding researchers in their experiments as illustrated in Table 1 is the flexural strength at the maximum load limit state. In 
addition, the flexural strength ratios $\left(\frac{M_{n}}{M_{\text {ext }}}\right)$ between the flexural strength values $\left(M_{n}\right)$ suggested in the AIJ, AISC, and EC4 design codes and the other flexural strength values measured in the experiments $\left(\boldsymbol{M}_{\text {ext }}\right)$ was referenced from the reports of each researcher. Furthermore, the flexural strength ratio of the strain compatibility ratio proposed without considering the confinement effect of concrete $\left(\frac{M_{n}}{M_{\text {ext }}}\right)$ is also listed.

Table 1 presents the flexural strength of the member measured in experiments $\left(\boldsymbol{M}_{\text {ext }}\right)$ and flexural strength values calculated by the equations of each design code and strain compatibility design approach $\left(M_{n}\right)$. The reference flexural strength ratio between the flexural strength measured in experiments and the flexural strength values calculated by codes $\left(\frac{M_{n}}{\boldsymbol{M}_{\text {ext }}}\right)$ is 1.0. If the flexural strength ratio is smaller than $1.0\left(\frac{M_{n}}{\boldsymbol{M}_{\boldsymbol{e x t}}}<\mathbf{1}\right)$, it indicates that the values estimated in accordance with the aforementioned design codes are conservative whereas, if it is bigger than $1.0\left(\frac{M_{n}}{M_{\text {ext }}}>\mathbf{1}\right)$, such values are overestimated in comparison with actual measurements measured in the experiments.

Table 1. Experimental and Analytical Comparison for concrete-filled square steel tube beam and column under pure bending

\begin{tabular}{|c|c|c|c|c|c|c|}
\hline \multirow{3}{*}{ Authors } & \multirow{3}{*}{$\begin{array}{c}\boldsymbol{M}_{\text {ext }} \\
{[\mathbf{k N} \cdot \mathbf{m}]}\end{array}$} & \multicolumn{5}{|c|}{$\frac{M_{n}}{M_{e x t}}$} \\
\hline & & \multirow{2}{*}{$\begin{array}{l}\text { AIJ/KSSC } \\
\text { (Confinement) }\end{array}$} & \multirow{2}{*}{$\begin{array}{c}\text { AISC } \\
\text { (Confinement) }\end{array}$} & \multirow{2}{*}{$\begin{array}{c}\text { Eurocode } 4 \\
\text { (Confinement) }\end{array}$} & \multicolumn{2}{|c|}{ SC } \\
\hline & & & & & $\begin{array}{c}\text { Un- } \\
\text { confinement }\end{array}$ & Confinement \\
\hline \multirow{4}{*}{$\begin{array}{c}\text { Tomii and Sakino } \\
\text { (1979) }\end{array}$} & 7.2 & 0.887 & 1.037 & 1.048 & 1.044 & 1.060 \\
\hline & 11 & 0.913 & 1.027 & 1.038 & 1.025 & 1.054 \\
\hline & 14 & 0.874 & 0.964 & 0.974 & 0.962 & 0.992 \\
\hline & 18.3 & 0.907 & 0.973 & 0.981 & 0.969 & 1.000 \\
\hline \multirow{12}{*}{$\begin{array}{l}\text { Lu and Kennedy } \\
\text { (1994) }\end{array}$} & 73.6 & 0.825 & 0.941 & 0.952 & 0.936 & 0.941 \\
\hline & 75.1 & 0.808 & 0.917 & 0.927 & 0.911 & 0.919 \\
\hline & 71.3 & 0.851 & 0.963 & 0.974 & 0.956 & 0.966 \\
\hline & 146.5 & 0.854 & 0.902 & 0.910 & 0.904 & 0.911 \\
\hline & 210.7 & 0.764 & 0.887 & 0.899 & 0.879 & 0.886 \\
\hline & 210.7 & 0.764 & 0.884 & 0.897 & 0.876 & 0.884 \\
\hline & 207.6 & 0.775 & 0.896 & 0.909 & 0.887 & 0.896 \\
\hline & 283.8 & 0.854 & 0.950 & 0.962 & 0.933 & 0.942 \\
\hline & 282.2 & 0.859 & 0.951 & 0.963 & 0.933 & 0.945 \\
\hline & 144.7 & 0.778 & 0.862 & 0.869 & 0.864 & 0.863 \\
\hline & 146.7 & 0.767 & 0.846 & 0.852 & 0.847 & 0.848 \\
\hline & 142.9 & 0.788 & 0.867 & 0.873 & 0.867 & 0.869 \\
\hline $\begin{array}{c}\text { Zhang and } \\
\text { Shahrooz (1997) }\end{array}$ & 318 & 0.839 & 0.949 & 0.948 & 0.949 & 0.958 \\
\hline \multirow{5}{*}{ Uy (2000) } & 27.9 & 0.732 & 0.868 & 0.860 & 0.875 & 0.874 \\
\hline & 42.4 & 0.746 & 0.898 & 0.890 & 0.905 & 0.903 \\
\hline & 62.6 & 0.722 & 0.856 & 0.848 & 0.861 & 0.870 \\
\hline & 103.5 & 0.770 & 0.941 & 0.933 & 0.947 & 0.950 \\
\hline & 153 & 0.810 & 1.003 & 0.996 & 1.009 & 1.011 \\
\hline Han (2004) & 29.34 & 0.880 & 0.876 & 0.955 & 0.938 & 0.971 \\
\hline
\end{tabular}




\begin{tabular}{ccccccc}
\hline & 30.16 & 0.856 & 0.852 & 0.946 & 0.929 & $\mathbf{0 . 9 5 6}$ \\
\cline { 2 - 6 } & 32.25 & 0.801 & 0.796 & 0.884 & 0.869 & $\mathbf{0 . 8 9 4}$ \\
\cline { 2 - 6 } & 31.69 & 0.815 & 0.810 & 0.900 & 0.884 & $\mathbf{0 . 9 0 9}$ \\
& 40.9 & 0.929 & 0.925 & 0.958 & 0.951 & $\mathbf{0 . 9 7 8}$ \\
& 41.54 & 0.915 & 0.911 & 0.943 & 0.936 & $\mathbf{0 . 9 6 2}$ \\
\cline { 2 - 6 } & 41.43 & 0.917 & 0.913 & 0.960 & 0.951 & $\mathbf{0 . 9 7 2}$ \\
\hline Probst (2010) & 42.61 & 0.892 & 0.888 & 0.934 & 0.924 & $\mathbf{0 . 9 4 6}$ \\
\hline Average value & 735 & 0.873 & 0.974 & 0.985 & 0.979 & $\mathbf{1 . 0 0 9}$ \\
(error ratio) & & 0.831 & 0.914 & 0.934 & 0.926 & $\mathbf{0 . 9 4 0}$ \\
& & $(16.9 \%)$ & $(8.6 \%)$ & $(6.6 \%)$ & $(7.6 \%)$ & $\mathbf{( 6 \% )}$ \\
\hline
\end{tabular}

The test data from the AIJ and KSSC (2011) design codes were found to be most conservative as presented in Table 4. According to the analysis, the flexural strength values estimated by the design codes and the design approach introduced by the authors in this paper were generally more conservative than the actual measurements made in the experiments. The $6 \%$ of errors were demonstrated by the proposed approach while larger errors as $17 \%$ were observed in the analytical calculations of other design codes. The strain compatibility design approach with consideration of the confinement effect of concrete is, therefore, more reliable than others.

\section{CONCLUSION}

Full composite action of all components-steel, concrete and reinforcing bars by shear anchors was assumed between steel sections and concrete in the strain compatibility method proposed by AISC in which a linear elastic-plastic stress distribution was assumed for the steel section and rebar and the concrete compressive stress distribution was presented by the Whitney stress block. Only "one" stress state based on full composite action of all components existed in this analysis. This approach is, thus, of limited accuracy to calculate neutral axis and nominal flexural capacity because Whitney stress block used to represent the concrete compressive stress distribution did not calculate actual compressive stress block. The nominal flexural moment capacity is not only overestimated, also is leading to the incorrect prediction of strain level of composite sections and incorrect design values. The proposed strain compatibility design approach enables, however, the calculation of accurate location of the neutral axis and corresponding stress states of the sections for concrete-filled square steel tubes, permitting one neutral axis from all the possible stress states to satisfy the equilibrium equation. Finally, the equilibrium equations for entire history of nominal flexural capacity based on Kent-Park concrete constitutive relationship were derived by the neutral axis represented by the correct stress state. The proposed approach permitted the analytical projection for the important design parameters including neutral axis, nominal moment capacity at each load limit state and at between those limit states and individual moment contributions of composite sections including steel section, concrete, reinforcing steels were obtained.

\section{ACKNOWLEDGEMENTS}

This work was supported by the Technology Transfer Center for National R\&D Program(TTC) grant funded by the Korea government(MSIP)(No. 2014K000239). 


\section{REFERENCES}

AISC (2011). ASCI Steel Construction Manual 14th, ANSI/AISC 360-10 Specification for Structural Steel Buildings, Chapter I Design of Composite Members, Chicago. American Institute of Steel Construction (AISC). (2011)

AISC (2011). AISC Examples Version 14.0, Chicago. American Institute of Steel Construction(AISC). (2011).

Eurocode 4: Design of Composite Steel and Concrete Structures, Part I: General rules and rules for buildings, Brussel. British Standards. (2004).

Standard for Structural Calculation of Steel Reinforced Concrete Structures, 5th Ed, Tokyo. Architectural Institute of Japan (AIJ). (2001).

Korean Steel Structure Design Code and Commentary - Load and Resistance Factored Design, Seoul. Korean Society of Steel Construction (KSSC). (2011).

Tomii, M., and Sakino, K. (1979). "Experimental Studies on the Ultimate Moment of Concrete Filled Square Steel Tubular Beam-Columns", Trans., A.I.K., 275, 55-63.

Zhao, X.L., and Grzebieta, R. (1999). "Void-Filled SHS Beams Subjected to Large Deformation Cyclic Bending”, Journal of Structural Engineering, 125, 1020-1027.

Zhang, W., and Shahrooz, B.M. (1997). "Analytical and Experimental Studies into Behavior of Concrete-Filled Tubular Columns", Cincinnati Infrastructure Institute, Univ. of Cincinnati. Report No. UC-CII 97/01.

Han , L.H. (2004). "Flexural behaviour of concrete-filled steel tubes", Journal of Construction Steel Research, Vol.60, 313-337.

Morino, S., and Tsuda, K. (2003). "Design and Construction of Concrete-Filled Steel Tube Column System in Japan", Earthquake Engineering and Engineering Seismology, 4(1), 51-73.

Mander, J.B., Priestley, M.J.N., and Park, R. (1988). "Theoretical Stress-Strain Model for Confined Concrete", Journal of Structural Engineering, 114, 1804-1826.

Karthik, M.M. and Mander, J.B. (2011). "Stress-Block Parameters for Unconfined Concrete Based on a Unified Stress-Strain Model", Journal of Structural Engineering; Technical Notes, 137, 270-273.

Popovics (1973). "A Numerical Approach to the Complete Stress-Strain Curve for Concrete", Cement and Concrete Research, 3(5), 583-599.

Hong, W.K., Kim, J.M., Park, S.C., Kim, S.I., Lee, S.G., Lee, H.C. and Yoon, K.J. (2009). "Composite Beam Composed of Steel and Pre-cast Concrete. (Modularized Hybrid System, MHS) Part II: Analytical Investigation”, Structural Design of Tall and Special Buildings, 18(12), 891-905.

Hong, W.K., Park, S.C., Kim, J.M., Lee, S.G., Kim, S.I., Yoon, K.J., and Lee, H.C. (2010). "Composite Beam Composed of Steel and Pre-cast Concrete. (Modularized Hybrid System, MHS) Part I: Experimental Investigation”, Structural Design of Tall and Special Buildings, 19(3), 275-289.

Uy, B. (2000). "Strength of Concrete Filled Steel Box Columns Incorporating Local Buckling", Journal of Structural Engineering, 126, 341-352.

Probst, A.D., Thomas, H.K. Kang, Ramseyer, C., and Kim, U. (2010). "Composite Flexural Behavior of Full-Scale Concrete-Filled Tubes without Axial Loads", Journal of Structural Engineering, 136, 1401-1412. 